\title{
3
}

\section{GÊNERO HUMANO E DIVERSIDADE HUMANA EM TEMPOS NEOLIBERAIS*}

Silvana Mara de Morais dos Santos

\section{INTRODUÇÃO}

Neste capítulo abordaremos a relação entre as determinações societárias, com ênfase na ofensiva neoliberal e suas implicações sobre o gênero humano e a diversidade humana. A crise do sistema do capital, aberta a partir da década de setenta do século XX, é um marco histórico fundamental para o entendimento do avassalador processo de decadência material e subjetiva a que está submetida a humanidade e, em particular, a classe trabalhadora em sua heterogeneidade e diversidade.

\section{TEMPO DE INDIVÍDUOS EXTRAVIADOS EM SUA DIVERSI- DADE E SUPEREXPLORADOS, FRAGMENTADOS E ATOR- MENTADOS}

No momento em que escrevemos este artigo vivenciamos uma crise societária de caráter estrutural e civilizatório que se encontra profundamente agravada pela pandemia - COVID-19 decorrente do novo coronavírus - que, além da interrupção de milhares de vidas em todo o mundo, agrava a realidade da barbárie capitalista, por acentuar: o desemprego; os processos de adoecimento e de superexploração da força de trabalho ${ }^{1}$; as violações de direitos e de formas variadas de violência decorrentes das relações sociais de classe, raça e sexo (relações patriarcais

*DOI - 10.29388/978-65-86678-37-6-0=f.67-82

${ }^{1}$ Segundo MARINI (2000, p. 160), a superexploração implica "maior exploração da força física do trabalhador, em contraposição à exploração resultante do aumento de sua produtividade e tende normalmente a expressar-se no fato de que a força de trabalho se remunere por baixo de seu valor real". 
de gênero); do não acesso público, gratuito, universal e de qualidade social da maioria da população às políticas da seguridade social, notadamente à saúde, mas também à educação; à segurança pública e a um conjunto de políticas sociais, de equipamentos e bens públicos.

As classes dominantes neste período de pandemia organizam estratégias para obter índices mais elevados de lucratividade e expansão de suas atividades mercantis em uma explícita contraposição entre acumulação/economia e defesa da vida. Em tese e de forma bastante cruel, as reações deletérias de certos governantes e grupos econômicos, confirmam a tendência de que, na sociedade capitalista, é de fato o atendimento voraz, voltado à acumulação em detrimento do atendimento às necessidades humanas que prevalece como regra. A pandemia, na verdade, explicita as características estruturais do sistema vigente: defesa intransigente da propriedade privada e busca desenfreada por processos de mercantilização de todas as dimensões da vida social.

Localizar nichos de mercado e se empenhar em conquistá-los em meio a uma pandemia da gravidade da COVID-19 é um triste e lamentável exemplo do caráter não civilizatório do sistema do capital em seu momento contemporâneo. A capacidade de enfrentamento de sua própria crise, desde os anos 70 do século XX, tem se constituído um campo aberto de destruição. De tal modo, que podemos afirmar que a vida no tempo presente parece nos provocar ao entendimento de que viver sob a égide dessas relações sociais significa conviver a cada instante com grandes tragédias que provocam destruição do meio ambiente, da vida humana com efetiva deterioração das condições materiais e subjetivas de existência.

Ademais, são muitas iniciativas em curso no Brasil, em face principalmente, do governo Bolsonaro e, no mundo inteiro reveladoras de um recrudescimento do conservadorismo de caráter reacionário e neofascista que representa uma ameaça real e cotidiana à convivência democrática e, no limite, à reprodução material do gênero humano.

Note-se que o neoconservadorismo não se apresenta como um sistema coerente de ideias, mas como um compósito ideológico constituído por doutrinas muito diversas e, até mesmo, colidentes 
entre si, tais como o libertarianismo, o fundamentalismo religioso e um anticomunismo reciclado (MOTA; RODRIGUES, 2020, p. 203).

Agrega-se ao quadro destrutivo, o não reconhecimento da diversidade humana, com ataques frequentes à população indígena, negra, às mulheres e às lésbicas, gays, bissexuais, travestis, transexuais e intersexuais (LGBTI) e demais indivíduos com modos de ser, identidade de gênero e orientação sexual que se apresente diferente dos padrões socialmente impostos.

Racismo, sexismo e LGBTfobia assumem visibilidade nos discursos de autoridades governamentais e, ao serem disseminados abertamente, legitimam a reprodução da violência institucional e da violência cometida pelas mais diferentes pessoas em suas vidas cotidianas. Prevalece, assim, a tendência de destruir práticas e procedimentos democráticos usando, de forma abusiva e autoritária, o Estado de direito, que segue numa aparência de normalidade, se valendo de medidas institucionais e legais negadoras e/ou que obstaculizam a democracia.

Como explicar esse sucesso crescente da extrema-direita? O primeiro elemento de explicação é o processo de globalização capitalista neoliberal — também um poderoso processo de homogeneização cultural forçada - que produz e reproduz, em escala europeia e planetária, os identity panics [pânicos de identidade], a obsessiva procura por fontes e raízes que leva a formas chauvinistas de religião, formas religiosas de nacionalismo, além de alimentar conflitos étnicos e confessionais. Diretamente relacionado a esse processo de hegemonia mundial neoliberal do capital financeiro há um outro fator importante: a crise econômica [...] (LOWY, 2015, p. 657).

Após décadas de implementação do neoliberalismo, que se constituiu em uma das estratégias de restauração desenvolvidas pelas classes dominantes no enfrentamento da crise capitalista, é pertinente afirmar que a redução drástica do papel do Estado na proteção social e sua ação política para assegurar regressão em contraposição à garantia de direitos históricos do trabalho é uma realidade que, aliada à ofensiva do capital 
contra a natureza e o trabalho socialmente protegido, põe em xeque à reprodução social da própria vida humana.

Nas particularidades da realidade brasileira, toda a engrenagem neoliberal desenvolvida a partir dos anos 1990 gerou implicações ainda mais acentuadas em face das características estruturais da formação sócio histórica com tardio e insuficiente reconhecimento de direitos humanos, da seguridade social e da diversidade humana. Somente com as lutas sociais que permearam a constituição de 1988 é que iniciamos um caminho em torno da construção de uma cultura política de direitos e, mesmo assim, com derrotas que deixaram excluídos da carta magna, dentre outros, os direitos da população não heterossexual e uma série de dispositivos da legislação social que deveriam ter sido regulamentados e não foram, em face das exigências do capital.

Neste sentido, assume prevalência a explícita orientação do Estado na defesa dos interesses econômicos de grupos e frações das classes dominantes. Ao desregulamentar os direitos do trabalho, regulamenta, via intervenção do Estado, os direitos do capital, materializando o que Mèszáros (2002) considerou como o funcionamento e dinâmica do sistema de sociometabolismo do capital, constituído pelo tripé capital, trabalho e Estado. E reafirma-se, também, certa confusão nos ideários dominantes não como algo fora da curva, mas como um modo particular de decadência ideológica. É pertinente a observação que segue sobre a ação ambígua do Estado, ainda que centrado nos interesses que tem que defender em cada momento histórico.

Apesar de parteiro e parceiro do capital desde o início dos tempos, os liberais de primeira hora, a exemplo de Adam Smith (LUX, 1993) viam o Estado como uma espécie de mal necessário, já que o liberalismo como visão social de mundo e prática, nasce em contraponto às amarras do Estado absoluto, que não comportava as liberdades de movimento que a expansão da produção de mercadorias, do dinheiro e do processo de valorização do capital requisitavam. $\mathrm{Na}$ verdade, o liberalismo tem para com o Estado, desde os primórdios até hoje, uma relação ambígua: que o requisita visceralmente e o repele compulsivamente (BEHRING, 2018, p. 41). 
Os processos contemporâneos de desregulamentação da legislação social e do trabalho se amparam nesta relação em que o Estado inserido na dinâmica da luta de classes, opera na direção hegemônica dos interesses das classes dominantes e realiza um conjunto de contrarreformas como parte integrante de um processo mais amplo de ajuste estrutural imposto aos países da periferia capitalista, sob o comando econômicopolítico das instituições financeiras multilaterais.

As iniciativas decorrentes dos programas de ajuste estrutural objetivaram as estratégias neoliberais direcionadas, dentre outras ações: à privatização dos serviços públicos; à redução do orçamento para políticas sociais e à adoção de programas focalizados para os setores mais pauperizados da população. A realidade se torna ainda mais grave pelos impactos decorrentes da aprovação da Emenda Constitucional (EC) no 95 que congelou por 20 anos os investimentos públicos e pela aprovação de um conjunto de contrarreformas, destacando-se a da previdência e a trabalhista.

Tudo isto gerou mudanças tão profundas no mundo do trabalho e de forma acelerada, também, nas condições subjetivas da classe trabalhadora, que desde os anos 80 do século XX sente fortemente as implicações oriundas do fim do equivocadamente denominado "socialismo real" e da ofensiva capitalista em face de sua crise estrutural.

Some a estas questões, as situações decorrentes dos fluxos migratórios completamente inseguros em busca de sobrevivência, submetendo, a graves riscos de morte, crianças e famílias inteiras das classes trabalhadoras que tentavam seguir viagem, abandonando histórias de vida e redes de familiares e amigos. Vale registrar que não se trata de migrações espontâneas, mas de uma sistemática dinâmica de expulsão completamente funcional à reprodução da economia global capitalista-heteropatriarcal-racista.

Os tempos neoliberais representam, portanto, além da avalanche destrutiva sobre as condições materiais de vida de amplos setores da população, uma espécie de aniquilamento das individualidades. Isto implica de fato no aprofundamento do ethos burguês que, consagra com mais vigor, o individualismo, a competitividade e processos de adoecimento, 
notadamente os que atingem e prejudicam a saúde mental, exacerbando os índices de suicídio.

A força degradante das condições de vida e de trabalho em situações de superexploração ou de desemprego pesa imensamente sobre a existência humana. Exatamente por isso fizemos alusão às relações sociais do mundo capitalista que gesta este tempo de indivíduos violados em sua diversidade; superexplorados em busca da sobrevivência, fragmentados em suas identidades e possibilidades de resistência e atormentados, com medo de adoecer, ficar desempregado ou ter que mudar de cidade para quem sabe conquistar alguma forma de sobrevivência. Mais que antes, é evidente o processo em curso de decadência ideológica. Integram esta trilha destrutiva, determinações que incidem sobre a vida cotidiana de forma tão acentuada que fica difícil a criação das estratégias de resistência, de luta e de enfrentamento político.

Todavia apesar das dificuldades tais iniciativas existem. Segundo Ferreira (2017, p. 59)

As nefastas consequências do programa neoliberal sobre as condições de vida da população levaram a processos de irrupção social nos anos 1990 e 2000, nos quais a América Latina foi o epicentro. Nos referimos aqui aos movimentos - antiglobalização - que se insurgiram no continente, desde o levante de Chiapas, no bojo da resistência contra o NAFTA, aos processos de mobilização de Seattle contra os Acordos de Livre Comércio no âmbito da Organização Mundial do Comércio - OMC (1999), às movimentações contra a ALCA em toda a América Latina, os Fóruns Sociais Mundiais organizados em paralelo e resistência do Fórum Econômico de Davos, e outros que se estenderam região adentro e mundo afora (AGUITON, 2002; SILVA, 2016) articulados em torno da resistência à mundialização neoliberal.

Cada experiência de organização dessas assinaladas revelou sujeitos coletivos constituindo as lutas sociais e dando visibilidade para uma agenda ampla, diversa e heterogênea de reivindicações. O grande desafio é superarmos o alto investimento das classes dominantes em minar cada iniciativa de resistência. A mundialização neoliberal atingiu de forma bastante contundente as expressões históricas de organização da classe tra- 
balhadora, tais como os sindicatos, partidos políticos de esquerda e os próprios movimentos sociais. Houve uma investida predatória sobre a cultura política de esquerda, na perspectiva de destituí-la de seu valor histórico e de sua relevância no cenário atual, além de uma profunda desqualificação das reivindicações e agenda política proveniente dos sujeitos políticos coletivos que participam das lutas sociais.

E, também, segmentos expressivos das esquerdas, em face das determinações societárias e de escolhas teórico-ético-político-ideológicas migraram seu pensamento e prática política para o universo do sistema e não mais contra o sistema. São alguns exemplos disso:

- a conciliação de classes nos processos eleitorais, no Brasil especialmente por meio da intervenção dos governos do Partido dos Trabalhadores (PT);

- a ruptura com o marxismo entre intelectuais de esquerda acusando-o de ser um pensamento necessariamente determinista;

- a adesão à perspectiva pós-moderna de intelectuais, movimentos sociais e partidos políticos identificados com a esquerda.

As classes dominantes disseminaram um clima ideológico de naturalização de sua dominação, uma espécie de "mantra" de que a crise atinge a todos indistintamente e/ou mais recentemente de que resulta diretamente da pandemia. Em ambos os sentidos, não teríamos muito o que fazer.

Apesar disso e observando as contradições da realidade, de março de 2020 quando iniciou a pandemia aos dias atuais, vimos o levante "vidas negras importam", protagonizado por movimento de mulheres negras - e contando com a participação de demais segmentos da população negra (homens, juventude) e de outros sujeitos individuais e coletivos - contra o genocídio e a violação de direitos cometidas pelo Estado, especialmente em seus aparelhos de segurança pública; as greves dos/as trabalhadores/as de entrega (aplicativos); atividades de paralisações e manifestações dos/as trabalhadores/as da saúde em defesa de melhores condições de trabalho e outras manifestações envolvendo movimentos de protesto e denúncia das violações de direitos humanos nas redes soci- 
ais. Movimentos feministas e de entidades de proteção dos direitos humanos, também, organizaram protestos em frente a um hospital público em Recife pela defesa do direito à vida de uma criança de 10 anos, evidenciando, mais uma vez, na pauta política, a defesa do aborto como uma questão de saúde pública e de liberdade/autonomia das mulheres, que devem ter o direito de decidir sobre a manutenção ou não da gravidez.

Foram muitas as iniciativas de denúncias e de formação política organizadas por variados grupos políticos, movimentos sociais, universidade e núcleos partidários com uso da tecnologia articulada às redes sociais. Há, portanto, iniciativas de problematização da realidade, na perspectiva de desnaturalizar as implicações do sistema capitalista-hetero patriarcal-racista.

A questão central é como ampliar e consolidar a organização da resistência da classe trabalhadora mediante este poderoso aparato ideológico das classes dominantes e a fortaleza das relações sociais de classe, de sexo e de raça, que se produzem e reproduzem de maneira coextensiva ${ }^{2}$. Não há cisões, nem "cortina de fumaça", tais relações se apresentam imbricadas no processo histórico e na dinâmica de organização da vida social, articulando exploração-dominação e apropriação.

No entanto, se por um lado, as classes dominantes têm historicamente conseguido, de forma intensa e precisa, articular economiapolítica-cultura e valores na manutenção de sua hegemonia, por outro lado, a classe trabalhadora e seus institutos político- organizativos tem tido no decurso do tempo, imensa dificuldade de elaborar a resistência a partir de uma perspectiva de totalidade.

Convivemos, assim, nos ambientes das esquerdas com uma espécie de campo minado, que ora reproduz visão economicista e descarta, de sua atenção estratégica, a resposta qualificada aos ataques à diversidade humana. Os sujeitos intelectuais e políticos optam nessa trilha economicista por estacionarem no lugar aparentemente seguro e nada revolucionário de enclausurar a economia dos demais complexos sociais.

\footnotetext{
${ }^{2}$ Kergoat (2010) propõe a concepção de "consubstancialidade" ao "[...] entrecruzamento dinâmico e complexo do conjunto de relações sociais, cada uma imprimindo sua marca nas outras, ajus tando-se às outras e construindo-se de maneira recíproca" (KERGOAT, 2010, p. 100).
} 
Isto implica que não buscam captar a força que tem a cultura, sempre mediada pelas determinações econômicas e o vigor dos processos de constituição dos sujeitos individuais em sujeitos políticos e da formação da consciência de classe, que nunca ocorre em um belo dia programado de sol. Diferente disso, é nas marés altas, baixas e às vezes invisíveis próprias da vida cotidiana que os indivíduos em toda sua heterogeneidade e diversidade vivenciam a realidade objetiva e, por vezes, fazem, de modo coletivo, o reconhecimento das razões subjetivas que permitem a organização da resistência e das lutas sociais.

Como não considerar a força organizativa das mulheres feministas (negras, lésbicas, heterossexuais, transexuais)? Como invisibilizar protestos e idas significativas às ruas (antes da pandemia) da população LGBTI? Que interlocução é possível estabelecer com a organização da população indígena lutando para permanecer existindo como povo que tem diferentes etnias e modos de ser? Quais lições históricas apreender com a organização da juventude lutando em defesa da escola e universidade públicas e/ou por transporte público?

Em cada um desses segmentos está em processo se gestando a consciência de classe. A leitura economicista separa estes sujeitos e suas reivindicações da classe trabalhadora. Preferem inserir a classe em uma redoma ilusória onde a luta social e a consciência de classe, supostamente sairiam prontas: sem movimento, sem contradições e sem os indivíduos que a formam em sua diversidade de raça, sexo, identidade de gênero, geracional e de inserção no mundo do trabalho.

Em outros termos, consagra-se, também, nos ambientes das esquerdas os mitos e ritos de uma leitura culturalista da realidade. De costas à perspectiva de totalidade no entendimento da vida social, elege a linguagem como a principal estratégia de luta. Sobressai profundos processos de autonomização dos complexos sociais da cultura, da política, da ética e dos direitos. A realidade é cindida em agendas, nomenclaturas e coletivos que além de não dialogarem entre si, rompem (ilusoriamente) com as determinações societárias e vivem, como se fosse possível, desconsiderar a força e as implicações da luta de classes. 


\section{CRÍTICA À CONCEPÇÃO ABSTRATA DE UNIVERSALIDA- DE FRENTE A DEFESA DO GÊNERO HUMANO E DA DI- VERSIDADE HUMANA}

O mundo burguês representou uma viragem sócio histórica radical frente ao mundo feudal. Nada seria mais como antes. Com a decadência da sociedade medieval, a modernidade ${ }^{3}$ se ergueu numa longa e tortuosa trajetória com a objetivação de um novo tipo de individualidade que é criadora e resultado das aspirações postas pelo desenvolvimento das forças produtivas, as quais demandaram mudanças na sociedade feudal, hierárquica e rigidamente constituída. Trata-se da "[...] elaboração de um ideal - o dos indivíduos autônomos, empreendedores e competitivos" (KONDER, 2000, p. 11).

A complexidade e intensidade das transformações foram radicais pela capacidade de abrangência e de alteração substantiva na vida social e individual. O capitalismo construiu um novo tipo de sociabilidade e de individualidade que corresponde à dinâmica societária naquilo que ela tem de avanço sobre as relações sociais pretéritas e no que promove de entraves/obstáculos ao pleno desenvolvimento humano. O capitalismo

[...] construiu não apenas os seus aparelhos materiais de produção mas, também, e, fundamentalmente, as suas premissas ideológicopolíticas. Fez 'terra arrasada' da maneira pela qual as sociedades anteriores, e cada um dos seus indivíduos, compreendiam a vida, a história, o mundo. Destruiu toda a institucionalidade anterior (DIAS, 1997, p. 27).

Indiscutivelmente o novo mundo do capital fez e segue fazendo "terra arrasada" de todas as relações sociais que funcionaram ou funcionam como uma espécie de trava ao seu projeto sempre atualizado de acumulação. Exatamente por isso neste momento histórico em que se desenvolve sua crise estrutural, ficamos frente a frente com sua capacida-

\footnotetext{
${ }^{3}$ Antônio Cícero (1995) chama atenção que o termo "moderno" se origina no advérbio latino modo que significa agora mesmo. Neste sentido, "[...] é sintomático que o uso da palavra moderno para designar o novo período histórico adote como marco inicial o momento em que se cons tate essa mudança na sensibilidade ao tempo. Começou a se generalizar a sensação de que o tempo histórico estava se acelerando" (CÍCERO apud KONDER, 2000, p. 12-13).
} 
de destrutiva. A barbárie é material e subjetiva, incide na vida concreta, alcança os valores, os modos de viver, de ser e sentir dos indivíduos em sua diversidade.

$\mathrm{Na}$ esteira do pensamento marxiano, entendemos que a sociedade não é a mera reunião ou junção de singularidades. Isto nos remete ao ponto de partida proposto por Marx. Trata-se dos indivíduos produzindo em sociedade. É, portanto, o caráter social da produção dos indivíduos, o seu ser em comum. Os nexos ontológicos entre o trabalho e os demais complexos sociais parciais e a forma sob a qual Marx valoriza e apreende a individualidade é fundamental no entendimento de que o indivíduo é ontologicamente um ser histórico, diverso e pertencente ao gênero humano.

Sob às particularidades do ethos burguês, os indivíduos estão acorrentados às prisões de uma universalidade abstrata que, ao desistoricizar suas condições de vida e de trabalho, impõe, como algo natural, à realidade da fragmentação e da redução da subjetividade ao mais profundo subjetivismo. Mas exatamente o que significa este ideário de universalidade abstrata?

Acusam o marxismo de aderir a um entendimento que reforçaria a concepção de universalidade abstrata. Nesse sentido, os indivíduos e a classe trabalhadora, essa última apontada como prioritária na abordagem marxista, foi pensada e caracterizada como se os indivíduos não tivessem/vivessem sexualidades, orientação sexual, identidade de gênero, etnia, raça, geração e outra dimensões que compõem a diversidade humana. Ou dito de modo coloquial, o marxismo seria refém de uma concepção de indivíduo que o aprisiona em "homem, branco e heterossexual" e isso se estende ao debate sobre as classes sociais. Assim, seus críticos deduzem contribuição indireta do marxismo para reforçar elementos da razão instrumental, própria da modernidade, além de ficar funcional a um certo conservadorismo moral, Nesse sentido, acaba legitimando a concepção de universalidade abstrata que, no extremo, trataria os indivíduos de forma a desconsiderar particularidades que alteram a vida cotidiana [...] (SILVA; SANTOS, 2018, p. 177).

Entendemos que a concepção de universalidade abstrata é merecedora de crítica radical principalmente pelas seguintes razões: 
- por sua incapacidade de apreender os indivíduos e as relações complexas com as classes sociais em sua historicidade;

- por não considerar as relações sociais de classe, raça e sexo como relações estruturantes, que se apresentam de modo imbricado e indissociável, pois são coextensivas e consubstanciais;

- por secundarizar a dimensão da subjetividade/personalidade e da individualidade frente a economia e a política;

- por não se apropriar dos fundamentos ontológico-sociais como caminho teórico-metodológico para entender que o real é concreto porque é síntese de múltiplas determinações.

Neste sentido, ao defendermos as concepções de gênero humano e de diversidade humana em uma perspectiva de totalidade, admitimos a heterogeneidade de concepções que utilizam ambos os termos com significados bem diferentes. Mais do que os duelos vigentes na produção do conhecimento que também são importantes, estamos reafirmando os ganhos da modernidade, notadamente a concepção de humanismo, da historicidade e da razão dialética (COUTINHO, 2010) que nos fornecem fundamentos teórico-ético-políticos capazes de superar reducionismos próprios de leituras deterministas ou que se pautam em uma perspectiva de subjetividade, nos termos da crítica realizada por Tonet (2013).

A perspectiva de totalidade na apreensão e análise da vida social nos possibilita romper com visões de baixa densidade histórica como as concepções economicistas e culturalistas e nos provocar para a tarefa mais complexa de entender a realidade em suas contradições e múltiplas determinações. É exatamente por isso que Marx não estava preocupado

[...] com o estabelecimento de uma ordem social simplesmente com base no poder de facto efetivo da maioria, para subjugar o interesse particular da minoria anteriormente dominante, mas com a superioridade de jure do socialismo sobre o capitalismo, entendido como capaz de liberar as energias auto realizadoras de todos os indivíduos, ao contrário do capitalismo, que nega a eles a possibilidade de autorrealização em benefício da desimpedida auto expansão do capital, não importando que as consequências desta sejam destrutivas (MÉSZÁROS, 1993, p. 215). 
Trata-se, portanto, do entendimento de que a tendência à decadência ideológica, identificada por Marx e retomada por Lukács, que se abre a partir de 1848 e que consagrou, em plena modernidade, uma desatenção profunda à história, flertando abertamente com processos de mistificação da realidade, por estimular um modo de pensar em defesa dos interesses das classes dominantes, ronda a dinâmica dos dias atuais atualizando sua forma e conteúdo.

A concepção de indivíduo enquanto singular e genérico evidencia o elo que nos torna partícipes do gênero humano. Fazemos a história em condições concretas que não foram escolhidas nem determinadas por nós, mas que, em cada tempo histórico, nos coloca em movimento com as conquistas pretéritas e com as possibilidades futuras. A diversidade como uma característica própria da individualidade permite a ruptura com a ideia de que é conservador tratar dos processos subjetivos e de individuação. A direção social dos fundamentos teóricos com os quais captamos os fenômenos importa muito. Entender a relação indivíduo singular/gênero humano/classe social e suas contradições, aprimoramentos e rebaixamentos no contexto da divisão social, racial e sexual do trabalho permanece como historicamente necessária e cara à perspectiva de totalidade.

\section{REFERÊNCIAS}

BEHRING, E. R. Estado no capitalismo: notas para uma leitura crítica do Brasil recente. In: BOSCHETTI, I.; BEHRING, E.; LIMA, R. de L. Marxismo, Política Social e Direitos. São Paulo: Cortez, 2018.

\section{COUTINHO, C N. O estruturalismo e a miséria da razão. São Pau-} lo: Expressão Popular, 2010.

DIAS, E. F. Textos didáticos: A liberdade (im)possível na ordem do capital - reestruturação produtiva e passivização. São Paulo: IFCH/ UNICAMP, 1997. 
DIÁRIO OFICIAL DA UNIÃO Seção 1 Emenda Constitucional N ${ }^{\circ}$ 95, - 16/12/2016, Página 2 . Disponível em: <http://www.planalto.gov.br/ccivil_03/constituicao/emendas/emc/emc95.htm>. Acesso em: 20 maio 2020.

FERREIRA, V. M. Apropriação do tempo de trabalho das mulheres nas políticas de saúde e reprodução social: uma análise de suas tendências. 2017. Tese (Doutorado - Serviço Social) - Universidade Federal de Pernambuco, Recife. 2017.

KERGOAT, D. Dinâmica e consubstancialidade das relações sociais. Novos estudos - CEBRAP, São Paulo, n. 86, mar. P. 93-103. 2010.

KONDER, L. Os sofrimentos do Homem Burguês. São Paulo: Editora Senac, 2000.

LOWY, M. Conservadorismo e extrema-direita na Europa e no Brasil. Revista Serviço Social e Sociedade, São Paulo, n. 124, out/dez. pp.652-664 2015.

MARINI, R. M. Dialética da dependência. Petrópolis: Vozes, 2000.

MÉSZÁROS, I. Filosofia, ideologia e ciência social: ensaios de negação e afirmação. São Paulo, Ensaio, 1993.

. Para Além do Capital. São Paulo: Boitempo Editorial, 2002.

MOTA, A. E.; RODRIGUES, M. Legado do Congresso da Virada em tempos de conservadorismo reacionário. Revista Katálysis, Florianópolis, v. 23, n. 2, p. 199-212, maio/ago. 2020.

SANTOS, S. M. M. Luta de classes e a questão da diversidade humana: debate atual e perspectivas político-teóricas. Revista Trabalho Necessário, Rio de Janeiro, v. 17, n. 32, jan/abril, 2019. Disponível em: 
<https://periodicos.uff.br/trabalhonecessario/article/view/28303/1643 4>. Acesso em: 24 ago. 2019.

SILVA, A. L.; SANTOS, S. M. de M. Legado do marxismo na análise do direito à cidade e da diversidade sexual. In: BOSCHET'TI, I.;

BEHRING, E.; LIMA, R. de L. (Orgs.) Marxismo, Política Social e Direitos. São Paulo: Cortez, 2018.

TONET, I. Método científico: uma abordagem ontológica. São Paulo: Instituto Lukács, 2013. 